Bangladesh Journal of Bioethics 2010; 1(2):20-23

\title{
ANIMAL RESEARCH IN DIABETES AND ETHICAL CONSIDERATION
}

\author{
Shamima Parvin Lasker ${ }^{1}$ Rishad Raihan ${ }^{2}$ \\ 1. Professor \& Head, Department of Anatomy, City Dental College, Dhaka, \\ 2. Business Information Technology, Kuala Lampur, Malaysia
}

\begin{abstract}
:
Research must have a clear statement that is the hypothesis. This hypothesis may involve a clinical question or pathophysiologic mechanism that cannot be tested ethically or appropriately using human subjects or alternative methods. Therefore, numerous animal models have been developed that mimic to human diabetes. They provide additional knowledge about and insight into disease processes and hopefully better methods for treatment or prevention of diabetes in humans. All scientific research involving the use of animals should begin with an ethical focus by examining the risk-benefit ratio (i.e., morbidity or mortality to the animal versus the potential importance of the knowledge acquired). The aim of this paper is to discuss these ethical aspects within the context of research on diabetes and form a framework for the decision-making process.
\end{abstract}

\section{Key words: Animal research, diabetes and ethics}

\section{Introduction:}

Diabetes researches have a hypothesis. This hypothesis may involve a clinical question or pathophysiological mechanism that cannot be tested ethically or appropriately using human subjects or alternative methods ${ }^{1}$. Therefore, animals have been routinely used in the field of diabetic research ${ }^{2}$. Numerous animal models have been developed that mimic to human disease states. One must assess an animal model on the basis of species appropriateness. The risk to the animal must then be minimized to obtain the best model to test the hypothesis 1 . It is legal and moral obligation of investigator who uses animals to ensure the minimization of pain and suffering of experimental subjects.

\section{Different type of diabetic model:}

Diabetes can be induced by surgical, pharmacological or genetic engineering means ${ }^{1}$. The surgical model of type I diabetes is done by total pancreatectomy, and the large animals (dog, canine, horse etc) usually is the choice of this model. This model was used by Banting and Best in 1920 in their studies for understanding the mechanism of diabetes leading to the discovery of insulin ${ }^{3,4}$. Total pancreatectomy is technically easiest in this species for its large size ( 5 ). But now a day this model for diabetes research is avoided because of 1) it requires major surgery, adequate postoperative analgesia, and good postoperative care with administration of antibiotics 2) the animal has little counter regulatory response to hypoglycemia and 3) chronic insulin supplementation is required ${ }^{1}$.

In pharmacological means diabetes may be induced via a number of drugs eg Streptozotocin and alloxan that selectively destroy pancreatic $\beta$ cells only ${ }^{6}$. This type of diabetes has been performed usually in small animal (e.g. cats, rabbits, guinipig and mice). The advantages of this model are 1) the use of these chemical agents leaves the remainder of pancreatic function intact; 2) Smaller animal models that have high rates of reproduction might be helpful in studies on genetics and the environment effect of diabetes and 3) smaller animal models are more economic. But the disadvantages of this model is that the drugs used can be toxic to other organ systems and the response to the drugs can be variable ${ }^{1}$.

Spontaneous models of diabetes, e.g. the BB (Bio breeding) rat and the NOD (Non Obese Diabetes) mouse. Destruction of $\beta$ cells is done in the $1 \mathrm{sr}$ month of age of animal and inbred in laboratories for many generations by selective mating for diabetes ${ }^{7}$. Major distinguishing features of this type of diabetic prone animals are good for genetically transmitted diseases study. The diabetic syndrome in this type of animals is highly reproducible (>50 percent incidence) and closely resembles insulin-dependent, ketosis-prone type I diabetes mellitus in humans. This model has been useful for studying immunologic mechanisms of diabetes and developing cyclosporin therapy for use in type I diabetes in humans ${ }^{8}$. In addition, this type of model are prone to long-term complications of diabetes eg the nephropathy, retinopathy cardiovascular complications 
and neuropathy, and that are very similar to complications in human diabetics ${ }^{9}$.

In generic engineering technique, a single gene that is responsible for insulin production is disrupted in embryonic stem cell and then transmitted along the germ cell line and develop to grow. Selective breeding will allow producing knockout animals ${ }^{2}$. Transgenic diabetic animal refer to incorporation of modify gene (insulin gene) in to the pronucleus of zygote and offspring will therefore over express the modify gene that play a key role to develop diabetes ${ }^{2}$. Advantage of these models are 1) a large number of diabetic animals can be produced to gain insight into the pathogenesis of diabetes, 2) it is the best choice for the follow up study to see the complications to other organs.

\section{Use of appropriate animal model:}

Several animal models of diabetes are currently available. It must be determined what particular animal model will provide new insight into the problem studied. Therefore, one must assess an animal model on the basis of species appropriateness ${ }^{10}$. The risk to the animal must then be minimized to obtain the best model to test the hypothesis. One must evaluate the appropriate use of these models to answer the hypothesis based on original contention that are clinically relevance.

\section{Against animal research:}

Some people regard animal experiment as an unjustified means of pursuing knowledge about human diabetes ${ }^{2}$. It is morally unjustifiable for mankind to make animals as subject for experiment that cause them discomfort as animal is enable to provide inform consent ${ }^{11,12}$. Moreover, no model of diabetes can accurately and completely reproducible the human syndrome ${ }^{9}$. Some argue that animals should not be used in experiments for provision of a substantial contribution to human welfare as most of cases researchers do not get expected result. It is obvious that biomedical research in which animals are used does not always provide an immediate benefit to humans ${ }^{13}$. This is often impossible to predict when animal models will develop the human disease ${ }^{14 .}$

In UK, as a result of public concern (regarding vivisection on unanaesthatic animal, research by entrain investigator), animal research is controlled by Animal scientific Procedure Act 1986, passed by Parliament. According to this regulation any experiment or other scientific procedure causing animal pain, distress, suffering or lasting harm are illegal unless covered by appropriate licences. Therefore, individual researcher must hold a Personal Licence (PIL- is granted after appropriate training of specific procedure on animal). PIL can only be used in conjunction with project licence ( PPL- it authorized specific work for specific purpose must indicate in details in protocol for each regulated procedure $)^{15}$. Furthermore, some diabetes charities that rely heavily on public donations may come under pressure not to fund animal research. Some donors seek reassurance that their money will not be used for animal research ${ }^{16}$.

Animal Welfare Committee (AWC) has already been introduced in many nations in Europe ${ }^{17}$. India adopted CPCSEA (Committee for the Purpose of Control and Supervision of Experiment on Animal) by parliament in $2004^{18}$.

\section{Bangladesh Perspective:}

Recently, an animal experimental ethical review committee (AEERC) is established by the Dhaka University in Bangladesh. Guidelines for animal study have been formulated in 2005. But it is not functioning in full swing. International Centre for Diarrhoeal Disease and Rehabilitation Bangladesh (ICDDRB) has institutional animal care committee. Bangladesh Medical Research Council (BMRC) over see the ethical issue on human as well as animal. Researchers seek the ethical clearance for the protocol funded by foreign or large fund by government only from these regulatory in Bangladesh ${ }^{19}$.

\section{Rs for protection of animal}

To reduce cruelty to animal research, 3-Rs (Reduction, Refinement and Replacement) are widely accepted, proposed by Russell and Burch in $1959^{20}$. India adopted 4-Rs (Reduction, Refinement Replacement and Rehabilitation) (18).Hans Martin Sass, a German philosopher, proposed 7-Rs (Reduction, Refinement, Replacement, Rehabilitation, Respect, Review and Relate) $)^{21}$ to protection animals from researchers. 
The investigator who uses animals has both a legal and moral obligation to ensure the minimization of pain and suffering of experimental subjects. Care should be taken to avoid duplicate research on animal. Strenuous efforts should be made to reduce the number of animals required for any particular study ${ }^{2}$. Previously pyrogen testing on animal is now replaced by computer simulation. Like the pyrogen testing computer model of diabetes should be invented ${ }^{2,22}$. Researcher should rehabilitate the survival animal from diabetes experiment. Chronic animal studies should be designed for maximum efficiency to obtain the highest possible rate of success and the maximum amount of information from each experimental subject.

The effects of stress on the animal causes increase heart rate that causes the animal discomfort. The animal must be little or fully unconscious at any time during the surgical/medical procedure to reduce stress. If the animal is allowed to remain diabetic for a protracted period, the end-organ disease may occur; how far it is necessary to allow the disease to progress is the concern. In no way, the animal should keep on starvation more than 48 hours for examining fasting glucose or induction of drug. Dose of anesthesia should be calculated according to body weight of animal before injection. Euthanasia should be done by over dose of anesthesia rather then decapitate or hit on the head of the animal. Investigators must closely monitor the animals and treat their metabolic disease as is appropriate to the research goals of the protocol. New investigators in this field should seek advice and counsel from experienced researchers. The experimental methods are continually refined and improved.

There is no doubt that the development of animal models of diabetes

Conclusion: has improved treatment and provided a better understanding of this disease. Hypothesis should be tested according to appropriate use of model for the animal walefare. Ethical issues must be addressed before the project begins and adhered to throughout the project to ensure the values of Rs for protection of animal in diabetes experiment.

\section{Reference:}

1. Frederick ES and Richard J T 1993. Ethical issues involved in the development of animal models for $\begin{array}{llllll}\text { Type I diabetes. ILAR Journal; } 35 & \text { (1): http://dels- }\end{array}$ old.nas.edu/ilar_n/ilarjournal/35_1/35_1Ethical.shtml

2. Rees DA and Alcolado CJ 2004. Animal models of diabetes mellitus. Diabet Med;22: 359-370.

3. S.P. Lasker, C.S. McLachlan, L. Wang, S.M.K. Ali, H.F. Jelinek. 2010 Journal of Diabetolog; $1(1): 1-8$

4. Bliss M. The discovery of insulin. Chicago: University of Chicago press, 2000.

5. Sarr, M. 1988. Pancreas. in Experimental Surgery and Physiology: Induced Animal Models of Human Disease. M.M. Swindle and R. J. Adams, eds. Baltimore, Md.: Williams \& Wilkins. Pp. 204-21

6. Lenzen S, Patter U. Alloxan ; History and mechanism odf acrion.diabetologia1988;31:337-342.

7. Artkinson M , Leiter EH1999. The NOF mouse model of insuline dependent diabetes: As good as it ge5ts? Nat Med; 5:601-604.

8. Stiller, C. R., J. Dupre, M. Gent, M. R. Jenner, P. A. Keown, A. Laupacis, R. Martell, N. W. Rodger, B. von Graffenried, and B. M. J. Wolfe. 1984. Effects of cyclosporine immunosuppression in insulin-dependent diabetes mellitus of recent onset. Science 223:1362-1367.

9. Marliss, E. B., A. F. Nakhooda, P. Poussier, and A. A. Sima. 1982. The diabetic syndrome of the "BB" Wistar rat: Possible relevance to type I (insulin-dependent) diabetes in man. Diabetologia 22:225-232.

10. Held, J. R.. 1983. Appropriate animal models. Ann. N.Y. Acad. Sci. 406:13-19.

11. British Union for the abolition of vivisention. http://www.buav.org

12. Petterson C, Eternal Treblinka. Out treatment of animals and the holocaust, New York: Lantern books, 2002.

13. Hoff, C. 1980. Immoral and moral uses of animals. N. Engl. J. Med. 302:115-118. 
14. Drs. Ray and Jean Greek 2009. Animals in Scientific Research: Medical Research - Diabetes http://www.navs.org/site/PageServer?pagename=ain_sci_medicalresearch_diabetes, seen in June 2009

15. Guidance of operation of the animals (scientific procedures) Act 1986: the stationary office 2000.

16. Diabetes UK Animal Research.Position staterment from diabetes UK.2002. http;//www.diabetes.org.UK.infocentre/state/animals.html

17. European federation of pharmaceutical industries and association 1999. Policy statement on the use of aniumal in research and development. EFPIA, 1999.

18. Pereira S, Tettamanti M 2005. Ahisma and alternatives - the concepts of the 4th R; the CPCSEA in India. ALTEX 22:3-6

19. Lasker SP, Hossain A 2009. Review of bioethics education in Bangladesh. Proceedings of $1^{\text {st }}$ UNESCO ethics workshop, Dhaka.

20. Russell WMS, Burch RL 1959. The principal of humane experimentation technique. London

21. Hans-Martin Sass 2008 Animal in research: 7-R principals and corporate responsibility .EJAIB Vol 18(3):74-75

22. PETEA (People for the Ethical Treatment of Animals) 2010. http://www.freshnews.in/why-peta-isagainst-more-usual-diabetes-research-18285 